\title{
Gerenciamento de limites interpessoais em distintas plataformas de mídias sociais por homens transgêneros
}

\author{
Management of interpersonal boundaries on different social media \\ platforms by transgender men
}

\section{Gestión de los límites interpersonales en diferentes plataformas de redes sociales por parte de hombres transgénero}

\author{
Sérgio Rodrigo da Silva Ferreira \\ Universidade Federal da Bahia - BA - Brasil \\ ORCID: https://orcid.org/0000-0002-9899-4378 \\ Endereço currículo Plataforma Lattes: http://lattes.cnpq.br/6898076743592293 \\ E-mail: sergiorodrigosf@gmail.com
}

\begin{abstract}
Resumo: Neste artigo apresentamos os resultados de uma pesquisa realizada com homens transgêneros usuários do Facebook na qual nos interessamos em estabelecer como as dimensões tecnopolíticas das plataformas de redes sociais atravessam suas produções nesses espaços, na perspectiva do gênero. Por meio de entrevistas, procuramos estabelecer usos e estratégias ligadas aos aspectos sociotécnicos dessa e de outras plataformas evidenciando diferenças e similaridades. O que os resultados sugerem é que o próprio fato de usarem as distintas plataformas de modos diferenciados caracteriza uma estratégia para ter alguma gerência de sua privacidade nos espaços on-line.
\end{abstract}

Palavras-chave: Plataformas de redes sociais. Facebook. Comunicação digital. Homens transgêneros. Gênero.

\begin{abstract}
In this article we present the results of a research carried out with transgender men who use Facebook, in which we are interested in thinking how the technopolitical dimensions of social media platforms cross their productions in these spaces, from a gender perspective. Therefore, through interviews, we seek to establish uses and strategies related to the socio-technical aspects of this and other platforms, showing differences and similarities. What the results suggest is that the very fact that they use the different platforms in different ways characterizes a strategy to have some management of their privacy in online spaces.
\end{abstract}

Keywords: Social networking platforms. Facebook. Digital communication. Transgender men. Gender. 


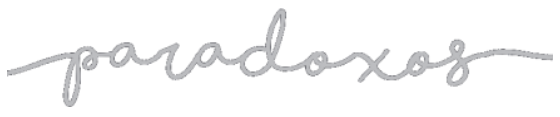

Gerenciamento de limites interpessoais

em distintas plataformas de mídias sociais por homens transgêneros

FERREIRA, 2020

Resumen: En este artículo presentamos los resultados de una investigación realizada con hombres transgénero que utilizan Facebook, en la que nos interesa pensar cómo las dimensiones tecnopoliticas de las plataformas de redes sociales cruzan sus producciones en estos espacios, desde una perspectiva de género. Por ello, a través de entrevistas, buscamos establecer usos y estrategias relacionados con los aspectos socio-técnicos de esta y otras plataformas, mostrando diferencias y similitudes. Lo que sugieren los resultados es que el mismo hecho de que utilicen las distintas plataformas de diferentes formas caracteriza una estrategia para tener cierta gestión de su privacidad en los espacios online.

Palabras clave: Plataformas de redes sociales. Facebook. Comunicación digital. Hombres transgénero. Género.

\section{Introdução}

O uso de plataformas de redes sociais está cada vez mais disseminado em nossa sociedade e, do ponto de vista das Humanidades Digitais, tem sido um fértil campo para entendermos modos de sociabilidade na contemporaneidade. Plataformas são dispositivos digitais que funcionam a partir de uma produção e intercâmbio de dados em lógicas econômicas mercadológicas, baseadas no engajamento dos seus usuários e que regulam, de certo modo, a ação deles em sua ambiência (D’ANDRÉA, 2020). As plataformas de redes sociais procuram disponibilizar e fomentar uma lógica sociotécnica de sociabilidade que produz uma interatividade entre sujeitos, interferindo em como eles gerenciam suas relações interpessoais.

Homens transgêneros não fogem a essa tendência e estão também utilizando essas plataformas. Aliás, as plataformas de mídias sociais e a Internet foram dispositivos fundamentais para a organização de homens trans e a massificação da possibilidade de se viver a própria identidade de gênero, especialmente nos anos 2000 e 2010 (ALMEIDA, 2019; ÁVILA, 2014; FERREIRA, 2020; NERY; MARANHÃO FILHO, 2013). Quando falamos de homens transgêneros (ou trans) estamos falando de pessoas que foram designadas com um gênero distinto do qual se identificam.

Em outras palavras, a transgeneridade masculina diz respeito às pessoas que não estão em conformidade com o gênero que lhes foi atribuído pela cisgeneridade 


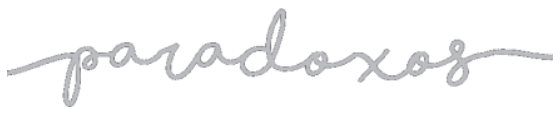

Gerenciamento de limites interpessoais em distintas plataformas de mídias sociais por homens transgêneros

FERREIRA, 2020

compulsória e que se constituem e se expressam como sujeitos no espectro das masculinidades. Entendemos cisgeneridade compulsória como a lógica normativa binarista e biologizante que atrela invariavelmente uma materialidade do corpo (em suas características sexuais) a uma identidade de gênero.

Neste artigo apresentamos os resultados de uma pesquisa realizada com homens trans usuários do Facebook na qual nos interessamos em pensar como as dimensões tecnopolíticas das plataformas de redes sociais atravessam suas produções de narrativas, imagens e presenças nesses espaços na perspectiva do gênero. Por meio de entrevistas com 15 desses homens, procuramos estabelecer usos e estratégias ligadas aos aspectos sociotécnicos dessa e de outras plataformas, evidenciando diferenças e similaridades. Portanto, nosso objetivo é entender como e se há uma gestão de específicos usos e relacionamentos com audiências próprias que dão entendimentos distintos às dimensões tecnopolíticas dessas plataformas, na perspectiva do gênero.

A escolha dos interlocutores se deu por conveniência ${ }^{1}$ : inicialmente foram contatados os sujeitos que faziam parte da minha própria rede social e, a partir deles, pelo método bola de neve ${ }^{2}$, foram agregados outros interlocutores. A partir de um roteiro de entrevista semi-estruturada, foram realizadas conversas em duas ou três sessões, de acordo com a necessidade da pesquisa e possibilidade dos interlocutores, no segundo semestre de 2018 e no primeiro de 2019.

Vale destacar que todos os nossos interlocutores têm acesso à Internet por celulares smartphones, e apenas um deles não acessa também por computador (desktop ou notebook). Além disso, dois deles acessam também por SmartTv e um por tablet. Alguns afirmaram que, entretanto, o uso de computadores tem função específica para trabalhos profissionais ou acadêmicos. Todos eles também disseram possuir acesso à Internet em casa e usarem pacotes de dados para acessar fora de casa ou o fazem por wifi público. Alguns destacaram o fato deste acesso acontecer em qualquer lugar ("literalmente em qualquer lugar", "em todos os lugares", "sempre conectado, levo meu celular até para o banheiro"). Houve ainda ressalvas para este acesso público

\footnotetext{
${ }^{1}$ A amostra por conveniência é uma "seleção de casos ou elementos que estão mais próximos, mais acessíveis ou com os quais é mais fácil ou mais barato trabalhar" (FRAGOSO; RECUERO; AMARAL, 2011). A vulnerabilidade da população em questão justifica a adoção de tal metodologia.

${ }^{2} \mathrm{O}$ método de amostragem bola de neve é não probabilístico, no qual os sujeitos que fazem interlocução com a pesquisa são sugeridos por outros interlocutores da pesquisa, a partir da rede de seus amigos e conhecidos.

DOI: http://doi.org/10.14393/par-v5n2-2020-57150 - Paradoxos, Uberlândia, v. 5, n. 2, p. 167-182, jul./dez. 2020 | 169
} 


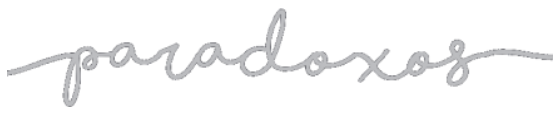

Gerenciamento de limites interpessoais

condicionado pelos fatores de segurança no local. Portanto, falamos com interlocutores que têm boas condições de conectividade, todos com aparelhos smartphones próprios e conectados à Internet em casa e fora dela.

Destacamos que temos como pressuposto um conceito de gênero que foi desenvolvido como categoria analítica para contestar a naturalização da diferença sexual entre os elementos de uma sociedade. Ele permite que, em análises históricas, nos demos conta de que diferença sexual como construção social dos "homens" e das "mulheres" posiciona esses sujeitos um em relação ao outro diferenciados por hierarquia e antagonismo (HARAWAY, 2004).

O estabelecimento da categoria gênero para dimensionar as diferenças sociais entre corpos sexuados causou reformulações nas políticas dessa natureza, especialmente após os anos 1960. Autoras feministas passaram a questionar e reconstruir, nessa perspectiva, a "construção de sentidos e tecnologias de sexo e gênero nas ciências da vida normalizadoras, liberais, terapêutico-intervencionistas, empiricistas e funcionalistas, (...) incluindo-se aí a psicologia, a psicanálise, a medicina, a biologia e a sociologia" (HARAWAY, 2004, p. 215). A categoria do gênero é usada para analisar a constituição do indivíduo na modernidade machista e racista, por uma ampla biopolítica de incitação ao discurso sobre sexualidade (HARAWAY, 2004).

As experiências comuns de homens trans têm estabelecido uma ideia compartilhada de corpo e subjetividade, inclusive nas plataformas de redes sociais online, a qual intentamos compreender apoiados nos estudos transfeministas. O transfeminismo, segundo Jaqueline Gomes de Jesus (2015), é uma linha de pensamento e prática do feminismo que

rediscute a subordinação morfológica do gênero (como construção psicossocial) ao sexo (como biologia), condicionada por processos históricos, criticando-a como uma prática social que tem servido como justificativa para a opressão sobre quaisquer pessoas cujos corpos não estão conformes "a norma binária homem/pênis e mulher/vagina" (p. 19).

O que temos é a contestação dos discursos que afirmam a naturalização dos corpos e das identidades postas por meio das articulações intersubjetivas e de (re)negociações dos sentidos das relações entre gênero, subjetividade e desejo. Desse modo, vamos ao encontro do que Donna Haraway (1995) afirma: os discursos de 


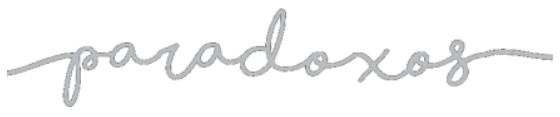

Gerenciamento de limites interpessoais

naturalização do corpo e da vida servem para que se impeça que se possam mudar as coisas. As tecnologias hormonais, cirúrgicas, digitais diluem cada vez mais as fronteiras do possível e aumentam nossa capacidade de (re)fazer nossos corpos, nosso gênero, nossa subjetividade, remoldando-nos e remodelando-nos.

Ao buscar estabelecer uma análise sobre os usos do Facebook, ficou evidente que essa análise precisava ser transmidiática, pois a narrativa dos próprios sujeitos sobre o uso do Facebook e do papel que a Internet exerceu no seu processo de transgenerização era atravessado por distintas plataformas (YouTube, Instagram, Twitter). Carlos D'Andrea (2020) destaca que os estudos sobre as plataformas devem considerar a interoperabilidade entre elas e a sua produção de um ecossistema distribuído multiplataforma que atua em um jogo de centralização e descentralização entre elas.

Do ponto de vista do usuário, ele não só está circulando em distintas plataformas como produtor e consumidor de conteúdo, mas também produzindo hibridizações de conteúdos entre elas. É bem comum, por exemplo, vermos impressões de telas ou mesmo links de uma plataforma circular em outra. Alguns recursos de compartilhamento em smartphones produzem isso tecnicamente quando usamos recursos como "compartilhar" e outras plataformas as quais fazemos parte são sugeridas para replicar o conteúdo.

Com o aumento e a crescente popularidade das plataformas de redes sociais, as práticas de expressar sobre si mudaram de maneira importante, principalmente pelo fato de que os usuários desses sites, geralmente, fazem divulgações de aspectos de sua vida para um público mais amplo, em vez de em pequenos grupos ou relacionamentos interpessoais. Isso se deve especialmente pelo fato desses sites conterem uma série de características, tais como visibilidade, capacidade de edição e persistência de conteúdo e associação de conexões, que formam interações e comportamentos de divulgação específicos. Tais conteúdos publicados possuem persistência na rede, replicabilidade, escalabilidade e buscabilidade, bem como uma dinâmica com audiência invisível, contextos colapsados e a fluidez entre o público e o privado (BOYD, 2011).

Nos interessa aqui entender a partir de uma certa compreensão desses aspectos de específicas plataformas de redes sociais por homens trans entrevistados que as usam, se criam - e se sim, quais são - estratégias próprias de gerenciamento em cada uma delas. Assim, na primeira parte deste trabalho descrevemos a utilização da plataforma Facebook 


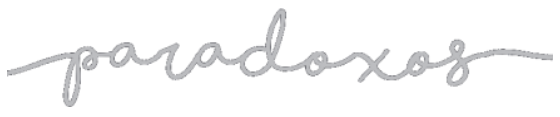

Gerenciamento de limites interpessoais em distintas plataformas de mídias sociais por homens transgêneros

FERREIRA, 2020

e as formas de acesso. Posteriormente traçamos a diferença de uso de outras plataformas, tais como assuntos e fatos que são compartilhados e os interesses em relação a elas.

Queremos aqui demarcar como essa diferenciação de uso funciona como um processo de regulação de fronteira pelo qual se gerencia o acesso dos outros às informações pessoais, que são controladas até um certo limite manipulando a profundidade, quantidade e qualidade de dados divulgados e frequência das exposições de si (DERLEGA; CHAIKIN, 1977; PETRONIO, 2002). A partir disso, os sujeitos podem jogar com alguns aspectos da sua privacidade quando eles têm um objetivo específico associado à sua digitalização de si (FERREIRA, 2020), tais como aumentar o nível de intimidade com seus pares para construir relacionamentos, criar uma impressão desejada, conseguir aprovação social e receber apoio e afetos dos outros, compartilhar experiências para produção de saberes de interesse mútuo, ajudando os indivíduos a construir suas próprias subjetividades e formular ideias e, por fim, aliviar o sofrimento através do processo de catarse, em que os indivíduos são capazes de liberar emoções compartilhando experiências ruins e medos (VITAK; KIM, 2014).

\section{Usos e especificidades do Facebook}

As motivações dos nossos interlocutores para o uso do Facebook são: se informar, debater, expressar-se, se organizar, conhecer, relacionar-se e ajudar outras pessoas, para fins profissionais e entreter-se. Um dos interesses é manter-se atualizado nos debates políticos presentes naquela plataforma de rede social, inclusive como o debate sobre gênero e transgeneridade tem sido mobilizado no Brasil, incluindo as suas violências, bem como os preconceitos raciais.

O Facebook é uma plataforma na qual é possível se informar sobre os eventos que estão acontecendo na cidade, inclusive grupo de estudos e palestras sobre questões de gênero, sexualidade e direitos humanos. Também se encontram links para materiais informativos, como livros (em drives, escaneados). Desse modo, é um espaço informativo e de formação sobre políticas trans e que podem ser aplicados em favor de si e de outras pessoas trans. 


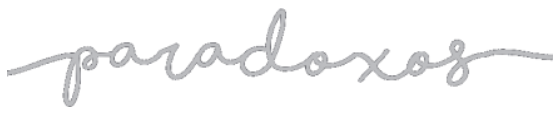

Gerenciamento de limites interpessoais

O Facebook é comparado às mídias mais tradicionais, como a televisão, como um meio de comunicação em que se tem contato mais direto com a informação, com menos interferência, diferente daquelas que são produzidas profissionalmente, como produtos jornalísticos. Seria uma forma de saber dos fatos diretamente com algumas fontes, quando os próprios sujeitos contam o que lhes ocorreu:

Eu não gosto muito de assistir televisão, eu assisto muito pouco, quem assiste mais aqui é a minha mãe, não gosto muito de assistir coisas assim, né? Notícias, coisas assim. Porque eu acho que na televisão, quer dizer, eu tenho certeza, como estudante de comunicação, eu sei como funciona, na televisão eles não colocam nada cru, às vezes eles ocultam algumas coisas, às vezes eles falam alguma coisa a mais, e muita coisa lá é censurada. E aí, eu acho que no Facebook você vê tudo no cru e você pode interagir com as pessoas, no cru, então eu acho que buscar informação e levar informação também é interessante por lá. E assim, pesquisar, saber como foi mesmo essas coisas que a gente não tem quando é na televisão a gente tem pelas redes sociais, que é quem está interagindo com o público às vezes acontecia alguma coisa e aí por ali contam certo ( $\mathrm{Nico}^{3}$, entrevista realizada em 2019).

Também há o interesse de participar dos debates a fim de criar conscientização social sobre as questões da transgeneridade. O Facebook é uma plataforma usada para compartilhamento de informações importantes para pessoas trans, como direcionamento jurídico, questões de saúde e oportunidades de trabalho. É, assim, um instrumento de educação política e social no contexto brasileiro.

Ela possibilita a expressão de ideias e o acesso a muita informação. Ainda possibilita compartilhar as suas visões e vivências do mundo, bem como acompanhar as dos outros também foi apontado como um dos interesses em estar nessa plataforma. Pode-se compartilhar conquistas e derrotas, alegrias e sofrimentos para motivar e inspirar outras pessoas.

É um espaço também em que é possível articular-se e organizar-se com outros sujeitos. Berilo ${ }^{4}$ (entrevistado em 2018) narrou, por exemplo, a experiência de organizar profissionais da saúde em torno de um grupo do Facebook para discutir as especificidades da saúde de pessoas trans em sua localidade. Outro interesse também é o de ampliar a construção de uma rede de pessoas que tenham o ponto de vista parecido a fim de possibilitar interações

\footnotetext{
${ }^{3} 20$ anos, negro, nordestino, graduando em publicidade e propaganda.

${ }^{4} 30$ anos, indígena, nortista, nutricionista. Nome fictício a pedido do interlocutor.

DOI: http://doi.org/10.14393/par-v5n2-2020-57150 - Paradoxos, Uberlândia, v. 5, n. 2, p. 167-182, jul./dez. 2020 | 173
} 


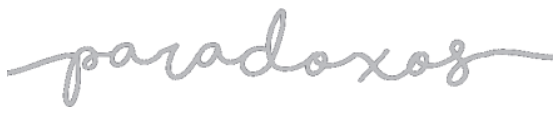

Gerenciamento de limites interpessoais

e convivências com uma certa qualidade de viés ideológico e gostos comuns, para além dos sujeitos em que se tem que conviver na territorialidade onde mora.

Outra motivação apontada pelos interlocutores foi a de poder estar em um lugar onde é possível conhecer uma quantidade vasta de pessoas. O Facebook ampliaria as possibilidades de interação com pessoas de distintos lugares do mundo. É nesse sentido que Daniel ${ }^{5}$ (entrevistado em 2019) nos disse que "sem face ${ }^{6}$ o mundo é bem pequeno aos nossos olhos". É uma rede que possibilita a específica conexão com outros homens trans para amizade ou como uma rede de compartilhamento de informação sobre transgeneridade e seus processos. Ela foi responsável por elucidar muitas dúvidas sobre o processo de transição e foi a fonte de informação por onde iniciá-la.

A plataforma possibilita a manutenção de contatos com relações forjadas no offline, como amigos, familiares e amigos de familiares e pessoas que auxiliaram e apoiaram no processo de transição. Também é uma ferramenta para dizer algo não diretamente a alguém, ao abordar temática de forma ambígua, as chamadas "indiretas".

Também é onde é possível conhecer outras narrativas e ter compreensão e solidariedade a elas. Alguns sujeitos que tem aceitação no seu círculo afetivo oferece apoio emocional a outros sujeitos trans que são abandonados pela família e por amigos, por não concordar com a sua condição trans. Possibilita que se auxiliem sujeitos de distintas formas, desde a obter informações cruciais às questões de transgeneridade, até mesmo a lidar com situações de violência ou auxiliar a ter acesso a serviços e empregos. Léo ${ }^{7}$ (entrevista realizada em 2018) explanou a potência dessa possibilidade que o Facebook abre:

Por meio do facebook, já consegui ajudar mais de 100 pessoas presencialmente e centenas virtualmente em questões relativas a direitos civis, penais e administrativos (onde incluo direitos a saúde pública, acesso aos aparelhos e diretrizes administrativas que demonstram o direito e muitos não sabem como usar e com isso são paulatinamente violados). Penso que seja uma ferramenta que me ajuda a ajudar as pessoas trans e algumas LGBs que me pedem tbm

Por fim, também foi apontada como característica de interesse para uso, o fato do Facebook ser uma ferramenta para contato profissional e divulgação de trabalho, sendo

\footnotetext{
527 anos, branco, sulista, designer gráfico.

${ }^{6}$ Abreviação de Facebook.

${ }^{7} 48$ anos, negro, sudestino, serigrafista, graduando em Direito. 


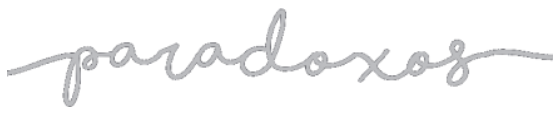

Gerenciamento de limites interpessoais

que muitos dos contatos iniciais com possíveis clientes acontecem pela plataforma. Também é um espaço para distrair-se. A plataforma possibilita, além disso, que se acesse páginas de artista e profissionais que são admirados por esses sujeitos.

Ao pensar o uso do Facebook, diferenciando-o de outras redes, os interlocutores afirmam que ela é uma rede marcadamente utilizada para a militância nas questões da transgeneridade, para um ciberativismo. Há uma perspectiva de que no Facebook se fala com o objetivo de conscientizar a sociedade ao expor suas vivências e suas crenças, sendo voltada para temas de utilidade pública.

O Facebook seria onde se compartilha ideias e questões de interesse do sujeito. Ali é o espaço onde se debate e compartilha informações de assuntos voltados para a transgeneridade, política, religião, raça, identidade de gênero, trabalho, música, cinema, gastronomia. Questões de relevância para outros homens trans são compartilhadas como informação para retificação de gênero e nome nas documentações, empresas que são pró-trans e informação de saúde voltada para homens trans. João Hugo ${ }^{8}$ (entrevista realizada em 2019) exemplificou uma dessas informações: “essa semana postei algo que foi relacionado à quando as pessoas retificam os seus nomes, nem sempre as informações dos antecedentes criminais alteram automaticamente, aí tem que ir no Instituto Pedro Mello9 para fazer atualização".

Haveria uma vocação do Facebook para textos, vídeos, imagens e notícias mais longos e "complexos" do que o que teria geralmente em outras plataformas e tal característica foi considerada positiva. Por outro lado, o caráter mais politizado da rede foi considerado excessivo. É uma plataforma usada para se atualizar, comunicar com outras pessoas e acompanhar a produção dos grupos, mais do que falar sobre si. É lugar de compartilhar memes engraçados. Ela também é usada para divulgação de eventos e manifestações. É, entretanto, uma plataforma que pode ser irritante.

As complicações de se viver uma adolescência trans e a solidão que tal condição proporcionaria foi motivo para um engajamento na rede só tardiamente, após o processo de transição. Nesse viés, o Facebook é considerado como uma rede mais ligada às relações que os sujeitos possuem nos espaços off-line, um prolongamento do mesmo.

\footnotetext{
825 anos, negro, nordestino, fotógrafo, produtor audiovisual.

${ }^{9}$ Em Salvador, é o instituto de identificação ligado à Secretaria de Segurança Pública, que realiza serviços de identificação civil, criminal e outros. 


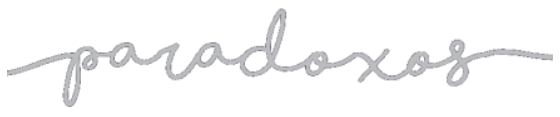

Gerenciamento de limites interpessoais

em distintas plataformas de mídias sociais por homens transgêneros

FERREIRA, 2020

Dessa forma, a solidão nos espaços off-line também se refletiria no ambiente on-line, especificamente do Facebook. Vale notar que o Facebook, diferente de outras plataformas, desenvolveu ferramentas para associar a identidade dos sujeitos on-line às suas identidades off-line, chamadas de políticas de autenticidade.

$\mathrm{Na}$ Central de ajuda do Facebook, o site deixa evidente que "o Facebook é uma comunidade na qual as pessoas usam suas identidades verdadeiras" (CENTRAL DE AJUDA, [s.d.], on-line). Desde 2014, o Facebook tem criado mecanismos para que as identidades dos perfis de usuários em seu site correspondam à identidade de uma pessoa off-line efetivamente associando nome, sobrenome, foto e data de nascimento ao perfil. Um dos principais eixos do documento de Padrão de Comunidade do site é "Autenticidade", onde as políticas descritas é que o Facebook quer garantir que "o conteúdo que as pessoas estão vendo no Facebook é autêntico"(FACEBOOK, 2019, on-line). O documento ainda diz que a empresa acredita que a autenticidade "cria um ambiente melhor para o compartilhamento, e é por isso que não queremos que as pessoas usem o Facebook para falsificar a própria identidade ou o que estão fazendo" (FACEBOOK, 2019, on-line).

A parte IV do documento é toda dedicada às questões da "Integridade e autenticidade". O item 19 é sobre "Falsificação" e começa afirmando que "a autenticidade é o pilar de nossa comunidade" e que acreditam que "as pessoas se responsabilizam mais pelo que dizem e fazem quando usam identidades genuínas" (FACEBOOK, 2019, on-line). Seria, pois, esse o motivo de exigirem "que as pessoas se conectem ao Facebook com o nome real” e que suas políticas de autenticidade visam "criar um ambiente seguro em que as pessoas possam confiar e se responsabilizar mutuamente". O que o Facebook chama de política de autenticidade é a proibição da falsificação da identidade, que inclui o respeito a suas "Políticas de nome" (que entre outras coisas proíbem uso de símbolos, título profissional ou religioso, palavras ou frases no lugar do nome e outros), ou falsificação da data de nascimento.

Perfis considerados "não autênticos" são bloqueados ou excluídos. Isso inclui nomes que o Facebook considera "não autêntico", "estranho" ou com palavras ofensivas (COSSETTI, 2014). Nesses casos os sujeitos têm que enviar cópias digitalizadas de seus documentos e, ainda que se cubra dados considerados sensíveis, é preciso que apareça 


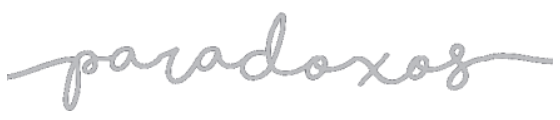

Gerenciamento de limites interpessoais

foto, nome completo e data de nascimento. É curioso notar que tal política do Facebook coaduna com a análise de que o site estaria desenvolvendo uma forma de identidade digital, função essa que é responsabilidade dos Estados Nacionais ${ }^{10}$.

Essa associação feita na perspectiva dos usuários talvez seja o reflexo dessas políticas e seus desdobramentos sobre as relações dos sujeitos on/off-line. Nesse sentido se atrela o revelar-se enquanto sujeito trans nas espacialidades distintas. Do mesmo modo, a incompreensão e dificuldade de acompanhar as "delicadas" "transformações psicológicas e emocionais" (Joaquim ${ }^{11}$, entrevista realizada em 2019) que homens trans e pessoas transmasculinas passam são reproduzidas na plataforma.

\section{Intersecções de outras plataformas de rede social}

Outros sites e aplicativos de plataformas de rede social citadas pelos interlocutores como aquelas que utilizam com certa frequência foram Instagram ${ }^{12}$, Twitter, Youtube e Tumblr. Além disso, WhatsApp, Telegram e Skype foram mencionados como mensageiros instantâneos. Outros sites e aplicativos elencados foram LinkedIn, Netflix, Gmail, Google Drive e Tinder. Isso sugere o que Anne Helmond vai chamar de "plataformização da web", que é a crescente adoção do modelo econômico e de infraestrutura baseado nas mídias sociais em que há a adesão a protocolos de acesso e intercâmbio de dados entre plataformas a partir das demandas de lucratividade das empresas proprietárias (D'ANDREA, 2017). No ponto de vista do usuário comum, cada vez mais a experiência de estar on-line se torna a própria experiência de utilização dessas plataformas.

Foi perguntado aos interlocutores se havia diferença nos usos das plataformas e aplicativos. Entre os usos específicos associados ao Instagram, a rede é utilizada para um conteúdo mais pessoal, a fotos de si mesmo (selfies) e publicação de

\footnotetext{
${ }^{10}$ Uma associação entre bancos e as gigantes empresas de tecnologia que querem ter maior controle das atividades na Internet, chamada Libra, em seu documento de apresentação expõe como um dos seus objetivos "desenvolver e promover um padrão de identidade aberto". Tal objetivo sugere a intenção de construir um poder soberano sobre informações sensíveis dos sujeitos de todo o mundo a fim de possibilitar um maior controle fiscal e tributário (ARRECHEA, 2019).

${ }^{11} 23$ anos, branco, sudestino, graduando em Direito.

${ }^{12}$ Além do Facebook, a rede que foi unanimidade de uso entre os interlocutores da pesquisa foi o Instagram. DOI: http://doi.org/10.14393/par-v5n2-2020-57150 - Paradoxos, Uberlândia, v. 5, n. 2, p. 167-182, jul./dez. 2020 | 177
} 


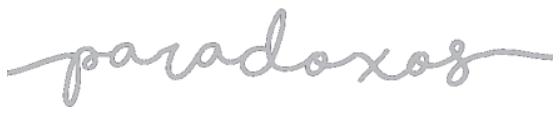

Gerenciamento de limites interpessoais

momentos de lazer. É onde se divulga aspectos do cotidiano. Foi considerada uma rede bem pessoal, local da exposição da intimidade.

Houve a opção pela rede social para publicação de conteúdo de cunho "mais pessoal" como estratégia de seleção de público. O fato de ser uma rede em que os pais não estão presentes por não dominarem a tecnologia (em contraposição ao Facebook) é o que possibilita essa separação de conteúdo/público. No caso específico, são relações paternas de não aceitação da condição transgênera do filho.

Se para alguns é uma plataforma considerada "menos séria", para outros é um espaço para divulgação de questões úteis como questões legais para a população trans e debates sobre gênero. O Instagram também é avaliado como uma rede em que se possibilitam discussões políticas e de conscientização sobre a causa trans.

Como espaço de ação é usada para publicação e visualização de fotos, assistir stories e compartilhamento de informações. É entendida como um "álbum de fotos" online onde se registra as mudanças corporais em decorrência do tratamento hormonal para a transgenerização. Ela possibilita acompanhar as suas transformações corporais no processo de transição, inclusive de outras pessoas, acompanhando a particularidade dos efeitos dos tratamentos sobre os corpos. Há um condicionamento do uso da rede a partir de uma certa segurança sobre a sua própria imagem, a exposição de si acontece a partir de conforto em adquirir uma imagem masculina.

Já a rede de microblogging Twitter é usada sem propósito explícito (para postar "coisas aleatórias" ou "qualquer groselha"), para publicar sobre aspectos do próprio cotidiano e conteúdo de humor, "menos político". É ainda um lugar de uma escrita sem preocupação de se de fato tem alguém lendo. É usada também apenas na perspectiva de consumo de conteúdo, mais do que da produção. Também é um espaço sem a presença de familiares, apenas de contatos e amigos, considerada uma rede em que os usuários são mais progressistas e dispostos ao diálogo.

O Youtube é usado para manutenção de canal voltado para o público trans, onde se fala sobre o próprio processo de transição, com a finalidade de auxiliar àqueles que ainda estão pensando sobre a questão. Já o Tumblr é considerada uma rede em que o sujeito é introduzido em questões importantes de cunho social, tais como "teorias de gênero, discussões sobre raça, sobre sexualidade, sobre o Estado", "sobre a brutalidade 


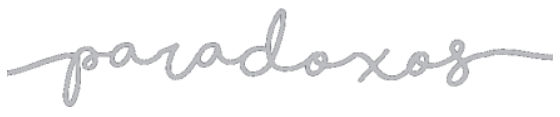

Gerenciamento de limites interpessoais

em distintas plataformas de mídias sociais por homens transgêneros

FERREIRA, 2020

policial" e violência "sofrida pela comunidade LGBT+ em geral, entre outras minorias" (Joaquim, entrevista realizada em 2018), como negros e indígenas. É uma rede em que é importante ter domínio da língua inglesa para acessar certos conteúdos, sendo, portanto, um espaço para prática bilíngue. Tumblr é um espaço de narrativa autobiográfica. Ao ser comparado ao Facebook, o Tumblr foi considerado uma rede em que se faz amizade na própria ambiência digital, enquanto que no Facebook, você encontra também amizades iniciadas no off-line. Desse modo, o sujeito se sente mais à vontade para se abrir e exporse afetivamente, contando com a compreensão desses amigos on-line.

Já o WhatsApp, segundo os interlocutores, é usado para contatos de "qualquer natureza", para "ficar de resenha" ou contato com amigos mais íntimos. Também é um lugar de ajuda a outras pessoas trans ou pessoas que precisam de algum suporte emocional. Algumas vezes o Whats App é um continuum de uma relação iniciada no Facebook. Após algum contato iniciado pelo Facebook em que se constata a necessidade de uma conversa mais próxima que exige acolhimento e demonstração de empatia, migra-se para o WhatsApp. Há, portanto, um uso do WhatsApp como a constituição de uma rede de apoio mútuo entre pessoas trans. Também é usado para tratar questões pontais, inclusive de convites e articulações da militância como rodas de conversa e participação em estudos e eventos. Já o Telegram aparece como uma espécie de local de refúgio dessas conversas quando elas se tornam demasiadas e atordoantes. Há também a associação do WhatsApp ao excesso de interação.

Por fim, alguns sujeitos não fazem diferenciação entre ações e públicos nas distintas plataformas e aplicativos. Essas ações teriam em comum a expressão de uma autenticidade do sujeito, o debate sobre assuntos similares em todas elas com respeito às diversidades de sujeitos em cada uma delas. Pode ainda que este conteúdo similar de uma plataforma a outra seja adaptado às suas dimensões sendo algumas vezes resumido.

\section{Gerenciamento temático e dos limites das relações nas plataformas}

Em nossas conversas com homens trans sobre seus usos de plataformas de redes sociais, como vimos até aqui, percebemos que os distintos usos entre elas, de modo geral, servem também para promover um certo gerenciamento do público e mesmo da 


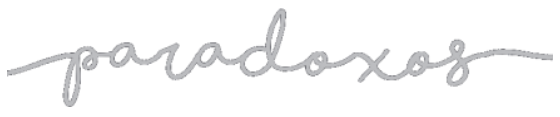

Gerenciamento de limites interpessoais

temática abordada, a partir de alguns entendimentos de suas características sociotécnicas (aspectos tecnológicos e usos dados pelos usuários).

Trabalhamos com a ideia de copropriedade e limites negociados da privacidade nesses contextos a partir de trabalho de Sandra Petronio (2002), para a qual o próprio entendimento de privacidade é de que ela seja um sentimento de que alguém pode se apropriar de algumas informações particulares, marcando assim limites que delineiam as noções de propriedade dos indivíduos sobre determinadas informações. Para Petronio, esses limites pessoais são gerenciados com o manejo das informações pessoais sobre si nas relações. E aqui percebemos que, nos contextos das relações produzidas nas plataformas de redes sociais, aspectos constituídos tecnicamente por elas também são considerados. Nessas plataformas há a criação da ideia de espaços seguros em que tecnicamente é possível haver algum controle da audiência para a qual se expõe, ainda que haja riscos.

A privacidade em rede invoca a constelação de dinâmicas de audiência, normas sociais e funcionalidade técnica que afeta os processos de divulgação, ocultação, dissimulação e interpretação de informações em um público em rede (BOYD, 2011). Se entendemos a privacidade como a gestão de fronteiras entre os sujeitos, aquilo que permitimos que o outro saiba ou não enquanto uma negociação sempre em processo, temos que dar conta também que a copropriedade desses dados on-line não permite que apenas estratégias individuais deem conta de um manejo dessas informações.

Como resultado desta pesquisa, temos que o Facebook é bastante usado por nossos interlocutores para o debate sobre gênero e transgeneridade, para se informar sobre os eventos, criar conscientização a partir da própria vivência e ampliar a construção de uma rede de pessoas trans. O Facebook, assim, é uma plataforma marcada por um discurso mais militante, inclusive por permitir textos mais longos e que geralmente é usado para abordagens mais complexas. Além disso, o Facebook, incentivado por suas políticas de autenticidade, tem forjado uma aproximação mais forte com as relações que se constituem no off-line. É uma rede que, ao permitir um certo gerenciamento dos acessos aos conteúdos do usuário, fomenta a criação de uma ideia de espacialidade segura em que há algum controle das pessoas que tem acesso a ele.

Já redes como Instagram e Twitter têm em comum o fato de serem plataformas em que alguns familiares não têm acesso simplesmente por não as usarem, dando alguma liberdade de 


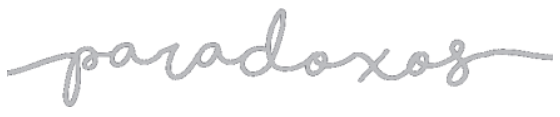

Gerenciamento de limites interpessoais em distintas plataformas de mídias sociais por homens transgêneros

FERREIRA, 2020

partilha do cotidiano e da intimidade. Também são espaços em que se é menos enfático em suas implicações políticas, sendo "menos sérias" e usadas mais para fins e entretenimento. Já o Youtube é usado para uma partilha de questões sobre processo de transição e produção comum com outros homens trans sobre essa questão. O Tumblr é tão sério e complexo como o Facebook, porém é menos acessível, sendo um local mais de formação.

O que esses resultados sugerem é que o próprio fato de usarem as distintas plataformas de modos diferenciados é uma estratégia para ter alguma gerencia de sua privacidade nos espaços on-line, que é produzida a partir tanto dos aspectos técnicos, enquanto possibilidade e vocação para uma determinada forma de escrita, produção de imagem e presença, mas também dos usos que essas plataformas vão ganhando a partir da apropriação dos distintos públicos.

\section{Referências}

ALMEIDA, Guilherme. Revisitando a aquarela das masculinidades. Revista Cult, $\mathrm{n}$. 242, p. 32-35, 2019.

ARRECHEA, Pascual. Facebook Libra de olho na sua identidade. 2019. Disponível em: https://livecoins.com.br/facebook-libra-de-olho-na-sua-identidade/. Acesso em: 15 dez. 2019.

ÁVILA, Simone. Transmasculinidades: a emergência de novas identidades políticas e sociais. Rio De Janeiro: Multifoco, 2014.

BOYD, Danah. Social Network Sites as Networked Publics: Affordances, Dynamics, and Implications. In: PAPACHARISSI, Zizi (org.). A Networked Self: Identity, community and culture on social network sites. Nova York: Routledge, 2011. p. 39-58. DOI: https://doi.org/10.4324/9780203876527-8.

CENTRAL DE AJUDA. Posso criar várias contas do Facebook?. Central de ajuda do Facebook. [s.d.]. Disponível em: https://web.facebook.com/help/975828035803295?_rdc=1\&_rdr. Acesso em: 15 dez. 2019.

COSSETTI, Melissa Cruz. Facebook exclui perfis brasileiros com "nomes estranhos". 2014. Disponível em: https://www.techtudo.com.br/noticias/noticia/2014/07/facebook-exclui-perfisde-usuarios-brasileiros-com-nomes-estranhos.html. Acesso em: 15 dez. 2019.

D'ANDREA, Carlos. Rumos a uma plataformização do social. Letras, n. 53, p. 17, 2017. Disponível em: http://letras.cidadescriativas.org.br/wpcontent/uploads/2018/12/Letras-53-PREVIA01.pdf. 


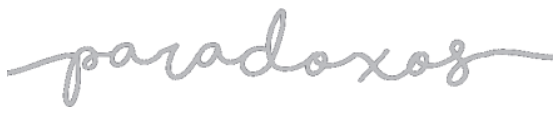

Gerenciamento de limites interpessoais em distintas plataformas de mídias sociais por homens transgêneros

FERREIRA, 2020

D’ANDRÉA, Carlos Frederico de Brito. Pesquisando plataformas online: conceitos e métodos. Salvador: Edufba, 2020. Disponível em: https://repositorio.ufba.br/ri/handle/ri/32043. Acesso em: 1 set. 2020.

DERLEGA, Valerian J.; CHAIKIN, Alan L. Privacy and Self-Disclosure in Social Relationships. Journal of Social Issues, [S. l.], v. 33, n. 3, p. 102-115, 1977. DOI: https://doi.org/10.1111/j.1540-4560.1977.tb01885.x.

FACEBOOK. Padrões da Comunidade. 2019. Disponível em: https://web.facebook.com/communitystandards/integrity_authenticity. Acesso em: 15 dez. 2019.

FERREIRA, Sérgio Rodrigo da Silva. Digitalização de si e transmasculinidades: a constituição de subjetividades gendradas e a produção de saberes no Facebook. 2020. Universidade Federal da Bahia, 2020.

FRAGOSO, Suely; RECUERO, Raquel; AMARAL, Adriana. Métodos de pesquisa para Internet. Porto Alegre: Sulina, 2011.

HARAWAY, Donna. "Gênero" para um dicionário marxista: a política sexual de uma palavra *. Cadernos Pagu, n. 22, p. 201-246, 2004. DOI: https://doi.org/10.1590/s010483332004000100009.

HARAWAY, Donna J. Ciencia, cyborgs y mujeres: La reinvención de la naturaleza. Madrid: Ediciones Cátedra, 1995.

JESUS, Jaqueline Gomes De. Interlocuções teóricas do pensamento transfeminista. In: Transfeminismo: teorias e práticas. Rio de Janeiro: Metanoia, 2015. p. 17-32.

NERY, João Walter; MARANHÃO FILHO, Eduardo Meinberg de Albuquerque. Transhomens no ciberespaço: micropolíticas das resistências (Eduardo Meinberg de Albuquerque Maranhão Filho, Org.). (In)Visibilidade Trans 2: História Agora, 2013.

PETRONIO, Sandra Sporbert. Boundaries of privacy: dialectics of disclosure: State University of New York Press, 2002.

VITAK, Jessica; KIM, Jinyoung. "You can't block people offline": Examining how facebook's affordances shape the disclosure process. In: Proceedings of the ACM Conference On Computer Supported Cooperative Work, CSCW 2014, New York, USA. Anais [...]. New York: Association for Computing Machinery, 2014. p. 461-474. Disponível em: http://dl.acm.org/citation.cfm?doid=2531602.2531672. Acesso em: 1 set. 2020. DOI: https://doi.org/10.1145/2531602.2531672. 